\title{
Learning in the Time of COVID-19: a Preclinical Student's Perspective
}

\author{
Eleanor Anne McClements ${ }^{1}$ (D)
}

Received: 14 April 2020 / Accepted: 5 October 2020 / Published online: 14 October 2020

(C) Academic Psychiatry 2020

As a medical student finishing my preclinical education in April 2020, the medical community's response to the COVID-19 broadened my understanding of the skills required to be a physician. The pandemic forced me to confront my discomfort with unpredictable circumstances, including those surrounding USMLE Step 1. Reflecting on my discomfort and the role uncertainty plays in the lives of those in the medical community, however, inspired me to develop the skills I need to better face uncertainty in my career. I found that personal engagement with concepts introduced during my psychiatry curriculum promoted resilience. In particular, I relied on selflessness and trust to connect with the medical community. Selflessness and trust are direct products of the mature defensive mechanisms of altruism and suppression, which I studied extensively but never engaged with on a personal level. I now believe that teaching psychiatric topics through self-reflection can help medical students identify ways to manage their own discomfort and cultivate resilience and personal growth. In this paper, I discuss how my preclinical education both encouraged and complicated my own development of trust and selflessness, how witnessing examples of trust and selflessness reconnected me with the medical community, and how personal engagement with the study of mature defense mechanisms promoted comfort with uncertainty.

As I studied for my delayed Step 1 exam during the early months of the pandemic, I read an Anki flashcard asking, "Name the four mature defense mechanisms." I recalled a mneumonic for mature defense mechanisms, SASH: Sublimation, Altruism, Suppression, and Humor. And then I flipped to the next card. This is how I moved through most of my psychiatry course - memorizing diagnostic criteria, drug side effects, and psychological principles. But I did not consider how these topics affect me. Instead I studied these ma-

Eleanor Anne McClements

eleanor.mcclements@umassmed.edu

1 University of Massachusetts Medical School, Worcester, MA, USA ture defense mechanisms - the unconscious precursors to acts of trust and selflessness - in a detached, competitive setting. I saw competition as the enemy of selflessness and trust. My medical school's pass-fail preclinical years limited academic competition. Studying for Step 1, however, made me more selfish with my time and energy. Although I worked to trust my school and administration to do their best for me and my community, I strained to trust my knowledge and work ethic as I studied for a repeatedly postponed test. I struggled to be selfless when I heard that Step 1 would define my ability to pursue a certain specialty and that I needed to outperform my peers to be a competitive applicant.

My perspective began to change when I focused on how my professors, mentors, and future colleagues modeled facing uncertainty. Uncertainty surrounding their patients' diagnoses, responses to treatment, and ability to afford care is ubiquitous. And this uncertainty undoubtedly grew during the coronavirus pandemic. Nevertheless, during my preclinical training, I saw providers sacrificing time with their families and trusting new teams in novel settings. I watched my teachers, who had refocused their careers on preclinical teaching after years of practicing medicine, don their white coats and brush up on their inpatient internal medicine in order to reenter the hospital workforce during the pandemic. While studying for Step 1 made me feel isolated, witnessing providers' selflessness and trust connected me to the medical community. When I feel supported within a community, the uncertainty does not recede, but it becomes far more manageable. Being grounded in a community assures me that if I am having an emotionally challenging day, I can share with my colleagues without judgment; and, if I am unable to solve a problem, I have a team around me who will jump in to help.

I used this change in perspective to engage with my Step 1 studies on a more personal level. In particular, I considered how I could harness my basic psychiatry knowledge to improve my own mental health. Altruism and suppression stuck out as useful mature defense mechanisms because they produce the conscious ideals of selflessness and trust. Altruism promotes selflessness. Suppression of anxiety surrounding 
lack of control results in trust. Although defense mechanisms are unconscious, learning them in the context of my own life enabled me to identify conscious actions that they elicit. I was able to be more mindful of these actions and how they served me as defense mechanisms after this realization. While studying for Step 1, for example, I was empowered to suppress anxieties about my test date being postponed and trust that everything would work out in part because I realized that this was a healthy way to manage these emotions.

I now believe that defense mechanisms can be taught through self-reflection. Self-reflection can clarify how manifestations of the mature defense mechanisms promote connection with community. In the preclinical setting, an instructor could ask students to reflect on a challenge that they faced and the ways in which they reacted positively or unproductively. Students would then investigate the defense mechanisms underlying their responses, promoting vertical reflection [1]. Integral to this exercise is the instructor modeling the process and allowing students to be free of judgment, analysis, or grading [2]. Teaching these topics through self-reflection can strengthen students' understanding. Moreover, self-reflection will enable students to identify areas of resilience and growth. Bringing the subconscious into students' consciousness allows for authenticity that we should not shy away from as learners and educators. In addition, this reflective learning, without associated grades or assessment, will promote community between students and faculty [1] by allowing vulnerability and connection through deeper common goals. Small group classes early in the preclinical years are the intuitive place for reflection; however, instructors should encourage students to be reflective in all aspects of their learning. Practicing these types of exercises during the preclinical curriculum will better prepare students to engage with reflective practices during their clerkship years, which can encourage self-awareness and self-directed learning. My hope is that further integration of reflection in medical education will foster the next generation of resilient and authentic physicians.

\section{Compliance with Ethical Standards}

Disclosures The author states that there is no conflict of interest.

\section{References}

1. Mann K, Gordon J, MacLeod A. Reflection and reflective practice in health professions education: a systematic review. Adv Health Sci Educ. 2009). https://doi-org.umassmed.idm.oclc.org/10.1007/ s10459-007-9090-2;14:595-621.

2. Schei E, Fuks A, Boudreau J. Reflection in medical education: intellectual humility, discovery, and know-how. Med Health Care Philos. 2019;22:167-78 https://doi-org.umassmed.idm.oclc.org/10.1007/ s11019-018-9878-2.

Publisher's Note Springer Nature remains neutral with regard to jurisdictional claims in published maps and institutional affiliations. 